\title{
Louis Harold Gray (November 10, 1905-July 9, 1965): a pioneer in radiobiology
}

\author{
Masaru Sekiya $^{1} \cdot$ Michio Yamasaki ${ }^{2}$
}

Published online: 6 October 2016

(C) Japanese Society of Radiological Technology and Japan Society of Medical Physics 2016

\section{Gray's personal background}

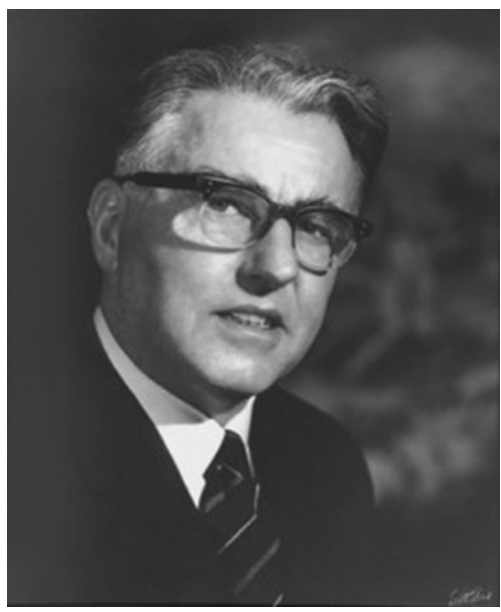

Louis Harold Gray was the only child of Harry and Amy Gray, born in London on November 10, 1905. His father was a lower class laborer employed at a post office as a telegraph operator in Britain's deeply rooted class system. His mother needed a side job to support the household economy.

Masaru Sekiya

mseki@clg.niigata-u.ac.jp

1 Department of Radiological Technology, Graduate School of Health Sciences, Niigata University, 2-746 Asahimachi-dori, Chuo-ku, Niigata 951-8518, Japan

2 Hokkaido University, 2665-7 Toppara, Nishi-ku, Niigata 950-1115, Japan
During his childhood, Gray went walking on Sunday mornings with his father in Barnes, Wimbledon Common, and Richmond Park. Gray's father was a man of few words, but was good at mathematics. On their walks, Gray's father would present him with problems to solve related to the purchase and sale of fruit, and Gray mentally calculated the answers. Gray's father was delighted that his son had answers to all the problems perfectly, regardless of how many problems were presented to him. This repeated practice, coupled with his innate genius, meant that Gray excelled at mathematics before beginning his formal education.

Gray entered the Latimer School at the age of five, and he earned excellent grades, and was granted a scholarship at the age of 13. The scholarship allowed him to attend Christ's Hospital ${ }^{1}$, a public school ${ }^{2}$. Gray lived in a dormitory, while he was there, which meant that he saw his parents only on holidays, but his parents visited him then and enjoyed talking with him about his grades.

\footnotetext{
${ }^{1}$ Christ's Hospital: Christ's Hospital was founded in London in 1552 by King Edward VI with financial support from a Christian organization. Its purpose was to serve as a hospital school for orphaned children of poor families. In 1902, the school was moved to its current location in the County of Sussex. The school continues to educate children from poor families. Yamasaki M, The Life of Gray [in Japanese], page 26.

${ }^{2}$ Public school: a traditional British privileged private junior high school. The origin of public school is believed to be as follows: children in wealthy families received individualized education at home rather than attending group schools, but children in families that were not so wealthy received group education, i.e., school education for the public. Yamasaki M, The Life of Gray [in Japanese], page 26 [1].
} 


\section{Gray's life at Christ's Hospital}

Gray's greatest joy upon entering Christ's Hospital was his encounter with science, and the only subjects Gray studied with passion were science and mathematics. Other subjects, such as Latin, French, and English, received only his minimal effort so as not to interfere with his study of science. These study habits were characteristic for students of science courses in public schools at the time.

While Gray was at Christ's Hospital, two teachers had major influences on his thinking: Charles Browne, head of the science department, and Mr. Hyde, who pushed Gray in mathematics. When Gray's performance in chemistry lagged behind that of his classmates, Mr. Browne helped him to catch up by assigning extra experiments and coursework over holidays. Mr. Browne was accomplished and knowledgeable in many areas. Another valuable teacher in Gray's life was Mr. Kelsey, a strict and unforgiving physics teacher. Mr. Kelsey was an outstanding physicist, and Gray enjoyed studying physics using Mr. Kelsey's excellent research notes (supplementary materials). At the age of 18, Gray became interested in molecular physics, exemplified by his voracious reading of a booklet by J. G. Crowther ${ }^{3}$. On Christmas in 1923, Gray received a scholarship to study at Trinity College, University of Cambridge (Fig. 1a).

\section{Gray's Cambridge days}

In 1924, Gray entered Trinity College, University of Cambridge. He had no previous interest in biology, and he entered Trinity College with no knowledge of the subject. Therefore, Mr. Browne gave Gray reading materials on biology and instructed him to read on holidays or whenever he felt an interest to correct his excessive bias toward physics. However, nuclear physics was a highly active discipline during this period, which left no room in Gray's thoughts about biology.

To score at the top of his class in the natural sciences (Part I) examination at the end of his second year, Gray worked hard studying physics, mathematics, and chemistry. He had begun this in his first year, and he earned a senior scholarship in the process. He continued to study hard for the natural sciences (Part II) examination and scored at the top of his class. Gray received the Trinity College Rouse Ball scholarship from 1927 to 1930.

In 1929, because of his outstanding academic performance, Gray became a researcher at the University of

\footnotetext{
3 James Gerald Crowther (1899-1983): British science historian who researched the social relations of science from various perspectives. In 1941, he confirmed that these relations in an overview of the history of science entitled The Social Relations of Science.
}

Cambridge's Cavendish Laboratory ${ }^{4}$ which was the top natural sciences laboratory in Britain (Fig. 2). At that time, Cavendish Laboratory was the home for many eminent scientists, including Ernest Rutherford ${ }^{5}$ as the head, Charles Thomson Rees Wilson, ${ }^{6}$ James Chadwick, ${ }^{7}$ Patrick Maynard Stuart Blackett, ${ }^{8}$ John Douglas Cockcroft, ${ }^{9}$ and Charles Drummond Ellis. Under the direction of Chadwick and Ellis, Gray undertook research in nuclear physics.

Gray's first research endeavor concerned a type of radiation now termed "cosmic rays". In 1929, his first paper was published, entitled "The Absorption of Penetrating Radiation", which primarily concerned $\gamma$-rays. He continued his research, and he published "The Scattering of Hard Gamma Rays: Pt. 1" (1930) and "The Scattering of Hard Gamma Rays: Pt. 2" (1931), which served as his doctoral dissertation. Gray thus produced many new discoveries in nuclear physics at Cavendish Laboratory.

In his personal life during his time at Cavendish Laboratory, Gray became engaged to a blind woman named Frieda Marjorie Picot. Frieda also was a student at the University of Cambridge, and she studied by reading books in Braille and having books read to her; these efforts resulted in her grades at the top of her class's graduation examinations in theology and English. In 1932, Gray and Frieda got married. Gray's research and personal life at Cavendish Laboratory were very fulfilling and happy for him.

\section{The turning point in Gray's life}

Gray was satisfied with his research work at Cavendish Laboratory. However, he began to think that there might be something else in the world demanding more urgent matters than nuclear physics. At that point, Gray unexpectedly

\footnotetext{
${ }^{4}$ Cavendish laboratory: An experimental physics laboratory established at the University of Cambridge in 1868-1869 that produced several Nobel Prize winners. Yamasaki M, The Life of Gray [in Japanese], page 31 .

5 Ernest Rutherford: The winner of the Nobel Prize in Chemistry (1908) for his research on the breakdown of chemical elements and the properties of radioactive substances.

${ }^{6}$ Charles Thomson Rees Wilson: The winner of the Nobel Prize in Physics (1927) for his method of using vapor to create trails of visible ions and particles with an ionization effect.

7 James Chadwick: The winner of the Nobel Prize in Physics (1935) for his discovery of the neutron.

${ }^{8}$ Patrick Maynard Stuart Blackett: The winner of the Nobel Prize in Physics (1948) for the development of Wilson's cloud chamber and the discovery of atomic nuclei and cosmic rays by the use of the cloud chamber.

9 John Douglas Cockcroft: The winner of the Nobel Prize in Physics (1951) for his pioneering work on the use of artificially accelerated particles to convert atomic nuclei. Yano T, The Nobel Prize [in Japanese] [2].
} 


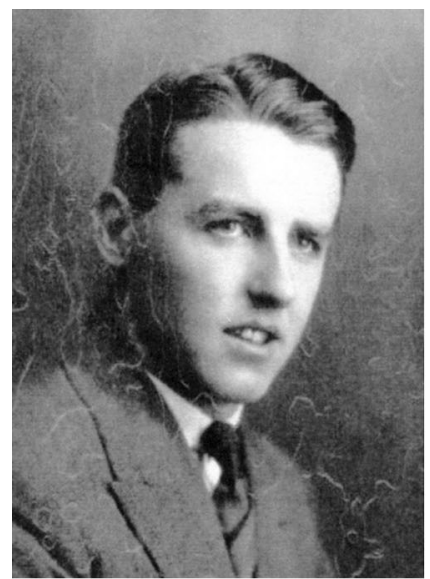

(a)

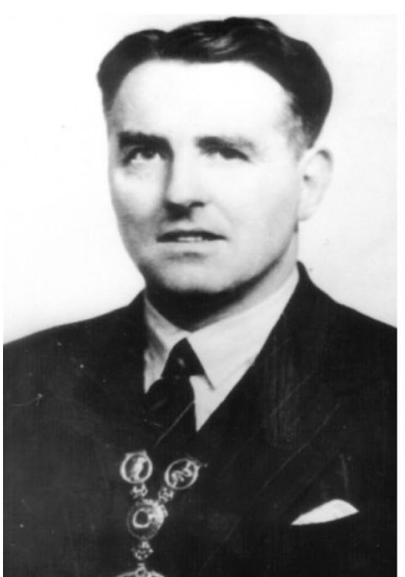

(b)

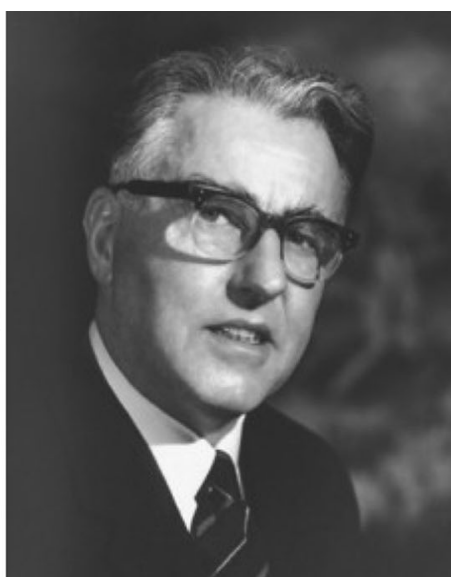

(c)
Fig. 1 Louis Harold Gray as a Fellow of Trinity College (Source: Collection of Dr. Michio Yamasaki), as b President of the British Institute of Radiology, 1950 (Source: Collection of Dr. Michio

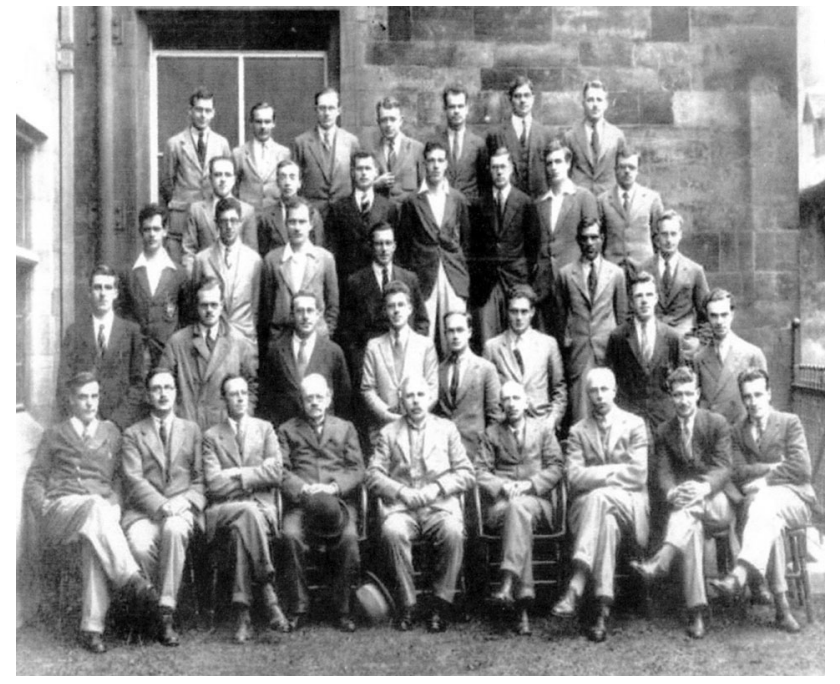

Fig. 2 Group photograph, Cavendish Laboratory, University of Cambridge (1930). Gray is shown at the far right in the top row. Sitting in the middle of the front row is Laboratory Director Ernest Rutherford. Source: Collection of Dr. Michio Yamasaki

heard from Chadwick that a London hospital was seeking a physicist to assist its efforts to measure the radium and $\mathrm{X}$-rays used in cancer treatments. Gray went to Mount Vernon Hospital and met with the hospital director, Sir Cuthbert Wallace, and the pathologist J. C. Mottram. Gray was utterly fascinated by these men. Mount Vernon Hospital had recently changed its specialization from tuberculosis to cancer and had no physicists on its staff. Gray joined Mount Vernon Hospital as a medical physicist in 1933.

At Mount Vernon Hospital, Gray had no technical assistants, which required him to operate machines and assemble equipment without help. He accompanied Sir
Yamasaki), and $\mathbf{c}$ in his older years (Source: http://www.enherts-tr. nhs.uk/patients-visitors/our...)

Wallace and Mottram on their rounds in the hospital, which gave him the opportunity to learn about cancer. He used all his free time to learn about biology by ravenously reading books recommended by Mottram.

Despite being a pathologist, Mottram apparently had no interest in classifying the diseases on which he made observations under the microscope in the laboratory. $\mathrm{He}$ was far more interested in the dynamics of growth processes. Using fava bean seeds, he attempted to compare the biological effects of X-rays and $\gamma$-rays, endeavoring to measure the energy of X-rays and $\gamma$-rays absorbed by the root apex. Gray and Mottram began biophysical measurements, using a Lindemann electrometer, which involved the constant recording of bioelectric potential distributions along the length of a fava bean root. For Gray, this undertaking led to his theory of the "cavity principle".

Hospital physicists were rare at that time, and Gray began using physics-based methods of dosimetry in radiotherapy. Using the experience that he had gained at the Cavendish Laboratory, he began to consider that, based on experiments aiming to determine the radiation absorbed dose in patients' cancer lesions, the answer could be obtained by calculation. During irradiation with X-rays or $\gamma$-rays, the energy absorbed in a substance occurs via the ionization of resultant secondary electrons. In general, measurements based on direct ionization are possible only with gases; with solids, they are usually impossible. Gray discovered that the amount of energy absorbed in a solid could be determined by the opening of a small cavity in the solid, filling the cavity with a certain gas, and measuring the electrical charge of the gas. In 1936, this method was published in "An Ionization Method for the Absolute Measurement of $\gamma$-ray Energy". The method is based on 
the so-called Bragg-Gray Principle ${ }^{10}$ or Bragg-Gray Equation.

In 1937, based on his experience with radium therapy dosimetry, Gray published a paper entitled "The Rate of Emission of Gamma-ray Energy by Radium B and Radium $\mathrm{C}$, and by Thorium B and Thorium C", which he followed with the publication of "Radiation Dosimetry Pt. I" and "Radiation Dosimetry Pt. II" in 1938. Gray wrote these papers with the expression of particular admiration and gratitude for the cooperation and skillfulness of technician J. G. Wyatt. Gray's field thus shifted from pure physics to biophysics. Gray stressed the need for physicists, clinicians, and biologists to work together on clinical dosimetry.

In 1936, Gray had begun a project at Mount Vernon Hospital to build a high-current accelerator, in which John Read of the Radium Beam Therapy Research Unit in London joined him. Gray boldly requested the British Empire Cancer Campaign (BECC) to purchase parts for a $400 \mathrm{kV}$ neutron generator. With its support, the neutron generator was completed in 1937. In 1938, in collaboration with F. Gordon Spear and Read, Gray used his neutron generator to conduct numerous studies on the effects of neutrons on living bodies, and he published the results in the journal Nature in a paper entitled "Biological Effects of Fast Neutrons". That same year, Read and Gray defined a dose unit that could be adapted equally to all the types of ionizing radiation. This definition accounted for the absorbed dose by tissue as well as the radiation dose to which the human body is exposed and which penetrates through it. Conceptually, this was identical to the future rad unit, but Gray and Read unfortunately named their unit the "energy unit". Fifteen years later, in 1953, the International Commission on Radiological Units and Measurement (ICRU) named the unit of absorbed radiation the "rad".

In 1940, Mottram, in collaboration with Gray, published a paper entitled "The Relative Response of the Skin of Mice to X-radiation and Gamma-radiation". This paper demonstrated that, when mice were irradiated with identical doses of X-rays and $\gamma$-rays, differences emerged in the resulting erythema and desquamation, with $\mathrm{X}$-rays having the greater effect. This led to the discovery of relative biological effectiveness (RBE). During World War II

\footnotetext{
10 The Bragg-Gray Principle: In 1912, William Henry Bragg suggested the existence of a certain relationship between the ionization occurring in the gas-filled cavity of an irradiated solid and the energy absorbed by the surrounding medium. Bragg was awarded the 1915 Nobel Prize in Physics for his research on the analysis of crystal structure by the means of X-rays. The principle is named the Bragg-Gray Principle because of Gray's elucidation based on a completely different theory. Yano T, The Nobel Prize [in Japanese] [2].
}

(WWII), Gray was invited to return to Cambridge to study neutrons; however, he declined, because he was a pacifist. Until the end of the war, Gray collected a massive amount of data to further radiotherapy for use in cancer treatment.

\section{The prime of Gray's life}

During WWII, nuclear physics research advanced rapidly, resulting in the completion of the atomic bomb and other military advancements and technical developments of highly rated and reliable high-energy radiation generators. After WWII, Gray took a position on the British Medical Research Council (MRC) as an expert in a specialized field. At the MRC, Gray served on the Committee on Medical and Biological Applications of Nuclear Physics, where he had a central role in radioprotection and tolerance doses, and he occasionally served as an adviser to the Minister of Health's advisory committee.

Shortly after WWII, the MRC endeavored to apply radiation in medicine as part of its efforts quickly to develop peaceful ways to use it. The first step was to provide financial support to Hammersmith Hospital to enable it to expand its radiotherapy facilities and conduct diverse research. In 1946, Gray joined the Hammersmith Hospital Radiotherapeutic Research Unit as the senior physicist, which was headed by radiotherapist Dr. Constance Wood. In this position, Gray's job was to develop techniques to promote the medical uses of radioactive isotopes and to apply a high-voltage generator to radiobiological research. At Hammersmith Hospital, Gray recruited new staff and acquired large-scale laboratory equipment, such as a medical cyclotron. The newly recruited staff included Normal Veall, Stephen Pelc, Alma Howard, and Shirley Carter. The year 1947 was busy for Gray, and he published numerous papers, such as "Structure Changes Produced in Microspores of Tradescantia by $\alpha$-radiation". In 1948, he published the results of his research from before and during WWII in a paper that he co-authored with John Read, entitled "Comparison of Lethal Effect of Neutrons and Gamma rays on Mouse Tumours (a) by Irradiation of Grafted Tumours in vivo (b) by Irradiation of Tumour Fragments in vitro". Gray also co-authored a paper with K. Tansley and F. Gordon Spear entitled "A Preliminary Note on Some Biological effects of Alpha Radiation on the Frog Tadpole". Then, in 1949, the following delays related to acceleration methods and financial problems, the cyclotron was completed. Gray's research team used neutrons and generated isotopes to begin radiobiological research.

The Radiation Research Society was founded in the United States after WWII to bring together physicists and biologists interested in the effects of radiation. At its first 
annual meeting held in Iowa in 1952, Gray presented "Some Characteristics of Biological Damage Induced by Ionizing Radiations" as a guest speaker (Fig. 1b). The content of this lecture, which was cutting-edge at the time, was at the highest level, revealing the full extent of Gray's knowledge and character. It clearly explained the complex issues in an irradiated organism and captured the attention of the many scientists. In addition, in 1952, he began studying hypoxic tumours and hyperbaric oxygen, areas in which clinicians had shown direct interests. In 1953, Gray published a paper with Oliver Scott entitled, "The Concentration of Oxygen Dissolved in Tissues at the Time of Irradiation as a Factor in Radiotherapy". In 1953, for the $32^{\text {nd }}$ Silvanus Thompson ${ }^{11}$ Memorial Lecture, Gray gave a lecture entitled "The Initiation and Development of Cellular Damage by Ionizing Radiation".

Gray later became a member of both the International Commission on Radiological Protection (ICRP) and the International Commission on Radiological Units and Measurement (ICRU). In those capacities, in addition to redefining their policy, Gray played a major part in refining the definitions of "doses" and "units". Gray demonstrated that he not only had grasped the basic principles as well as anyone, but it was clear that he had brilliantly integrated opposing views. He was on Committee 4 (ionizing radiation, electrons, neutrons, and protons limited to $3 \mathrm{MeV}$ for protection) of the ICRP, where he served two terms (1953-1956 and 1956-1959). In 1958, Gray became the vice chairman of the ICRU (Fig. 3).

\section{Gray Laboratory}

Due to differences in opinion on the use of a neutron radiotherapy device and other things, the relationship between Gray and Wood grew strained, leading to Gray's dismissal from Hammersmith in 1953. In November of that year, the BECC recommended Gray as a Nuffield Foundation $^{12}$ special researcher, and it offered him financial support and favorable considerations to support his appointment to another post. Thus, a new radiobiological research unit was established at Mount Vernon Hospital, and Gray was named its director.

Upon his return to Mount Vernon Hospital in September 1954, Gray led the staff members who were engaged in radiobiological research and those dedicated to applying

\footnotetext{
11 Silvanus Thompson: The first president of the Röntgen Society, the forerunner of the British Institute of Radiology.

12 Nuffield foundation: William Richard Morris, 1st Viscount Nuffield, founded Morris Motors and was a philanthropist. In 1943, Morris donated $£ 10$ million to establish the Nuffield Foundation to promote education and social welfare. Another donation by Morris was used to establish Nuffield College at the University of Oxford.
}

nuclear physics to medical biology. These Hammersmith hospital staff members included J. W. Boag, Alma Howard, Oliver Scott, and R. R. Ransley. However, the research unit building was a threadbare facility, erected as an emergency hospital wing during WWII, and it was not even heated. Despite these circumstances, Gray and his team were constantly absorbed in their research. The provisional Mount Vernon Hospital research unit also welcomed Eleanor Deschner, Ernest Pollard, and Alan Conger, all of whom were collaborating researchers from the US. In 1956, a donation from an anonymous benefactor enabled the completion of a new building at Mount Vernon Hospital. This building was named the Gray Laboratory.

The opening ceremony for the new research facility was held on May 20, 1957, with the Duke of Devonshire, as the Chairman of the BECC, in attendance. This new facility also served as a Radiation Research Visiting Club, and it welcomed many visitors from within Britain and from all the world. Gray formed the Association of Radiation Research, similar to the American Radiation Research Society, and served as its first chair from 1958 to 1960. This association later developed into the British Association for Radiation Research. While Gray was chairman of the Association of Radiation Research, informal inquiries regarding hosting of the second International Congress of Radiation Research ${ }^{13}$ in Britain were made. Although the newly formed Association of Radiation Research was believed to lack the financial support to host the Congress, the Association ultimately agreed to do it, and Gray headed the organizing committee. In 1957, Gray published "Radiobiology and Cancer" and "Oxygenation in Radiotherapy. 1. Radiobiology Considerations".

Gray was busy through the late 1950s. In 1958, he published "The Influence of Oxygen on the Radiosensitivity of Cells and Tissues" and "Effect of Nitric Oxide on the Radiosensitivity of Tumour Cells", the latter article coauthored with F. O. Green and C. A. Hawes. In 1959, Gray published papers, including "Cellular Radiobiology" and "The Influence of Oxygen and Peroxide on the Response of Mammalian Cells and Tissues to Ionizing Radiations", the latter of which was co-authored with H. B. Chase and Eleanor Deschner. In 1960, Gray reported his research in "The Influence of Pre-irradiation Storage of Ascites Tumour Cells on Radiation Sensitivity". During these years, Gray was particularly interested in the electrochemical cell developed by Paul Hersch to measure oxygen tension, and he conducted experiments. Based on those experiments, Gray and microbiologist David Dewey appealed to radiobiologists to be more careful in adjusting the oxygen level during irradiation.

\footnotetext{
${ }^{13}$ International Congress of Radiation Research: The first Congress took place in 1958 in Burlington, Vermont, US.
} 


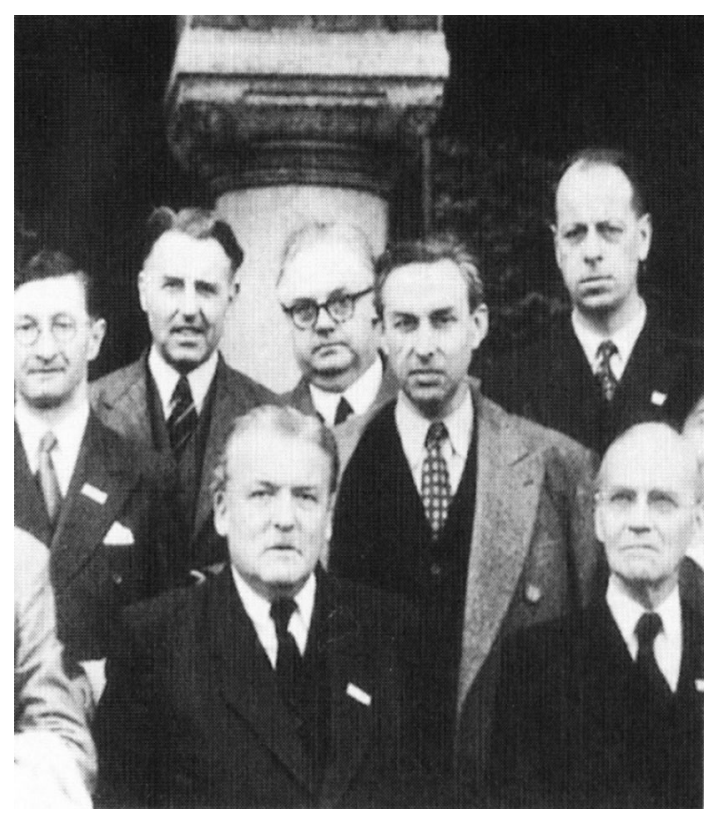

Fig. 3 Photograph from the ICRP-ICRU held in Stockholm in 1952. Gray and Sievert (second and third from left in the back) are photographed next to each other [1 P. 23]

In 1961, Gray began conducting numerous experiments on radiation carcinogenesis to determine whether radiation functions as a trigger. He consequently published several papers on the subject, including "Elementary Mechanisms of the Action of Radiation", "Relationship of Biological Dose to Physical Measurement", "Radiobiologic Basis of Oxygen as a Modifying Factor in Radiation Therapy", "Xrays in the Service of Cancer" and "Some Distinguishing Features of the Initiation of Biological Damage by Photon and Ionizing Radiation". In August 1962, with Gray as chair of the organizing committee, the second International Congress of Radiation Research was successfully held in Harrogate, England. Having ensured the success of the International Congress, Gray went on to play an active part in the formation of the International Association for Radiation Research. However, due to the enduring stress under which he was working, he was utterly exhausted. His friends and colleagues urged him to step away from research for a while and rest, but he refused.

In the early 1963, Gray's friends' fears were realized when Gray suffered from a serious stroke. He focused on his rehabilitation and, 5 months later, like a phoenix rising from the ashes, he returned to research. In March 1964, despite only just recovering from his illness, Gray accepted an invitation from the Japanese National Institute of Radiological Sciences and the Japan Radiation Research Society to lecture in Japan. The invitation was part of the technical assistance received by Japan from the International Atomic Energy Agency (IAEA). Gray was in Japan from March 19 to April 7, lecturing on radiobiology at the National Institute of Radiological Sciences, The University of Tokyo, Kyoto University, and elsewhere. Upon his return, Gray threw himself (along with H. B. Hewitt) into fresh research on tumour transplantation. Their experiments on survival curves in irradiated animal colonies began to yield worthwhile results, and, in 1965, Gray wrote "Radiation Biology and Cancer. Cellular Radiation Biology". However, in that same year, on July 9, Gray suddenly suffered a second stroke and passed away, leaving his family, many friends, and subordinates shocked at the news of his sudden death (Fig. 1c).

Gray received many awards and honors, including the Roentgen Award of the British Institute of Radiology (1938), the Sloan Kettering Institute's Katharine Berkan Judd Award (1954), the Barclay Medal (1960), and the M. D. Anderson Hospital and Tumour Institute's Bertner Foundation Award (1964). In 1961, he was selected as a Fellow of the Royal Society. In 1962, he was awarded an Honorary Degree of Doctor of Science from the University of Leeds.

In 1975, exactly 10 years after the death of Louis Howard Gray, the man who established the new academic field of radiobiology, ICRU, and ICRP proposed, and the Comité International des Poids et Mesures (CIPM) adopted, the Gray (Gy) as the official name of the unit of absorbed dosage, thus establishing Gray's name and legacy.

\section{References}

1. Yamasaki M. The life of Gray: A pioneer in radiobiology. Niigata: Kokodo Shoten; 2000 (in Japanese).

2. Yano T. The Nobel Prize: the universal language of the 20th Century. Tokyo: Chuokoron-Shinsha; 1988 (in Japanese). 